\title{
Cell Death in the Midbrain of the Murine Mutation weaver
}

\author{
Suzanne Roffler-Tarlov, ${ }^{1}$ Baby Martin, ${ }^{1}$ Ann M. Graybiel, ${ }^{2}$ and John S. Kauer ${ }^{1}$ \\ 1 Department of Neuroscience, Tufts University School of Medicine, Boston, Massachusetts 02111, and 2Department of \\ Brain and Cognitive Sciences, Massachusetts Institute of Technology, Cambridge, Massachusetts 02139
}

The midbrain of the adult homozygous weaver ( $W v / W v$ ) mouse is notable for a reduction in the numbers of dopaminecontaining cells in the substantia nigra (A9) and the retrorubral nucleus (A8). We have determined that the reduction in tyrosine hydroxylase $(\mathrm{TH})$-positive neurons in the ventral midbrain of the weaver is attributable to the loss of neurons after postnatal day 7 (P7). Because the number and spatial distribution of $\mathrm{TH}-$ positive mesencephalic neurons in $w v / w v$, heterozygous weavers $(+/ w v)$, and wild-type mice are not significantly different on $P 7$, we conclude that the early developmental steps of proliferation and migration have taken place normally in the mutant. Although numbers and distribution of cells are normal in the $w v / w v$ on $\mathrm{P} 7$, the appearance of the TH-stained ventral midbrain is abnormal because of the paucity of TH-stained dendritic processes. The ventrally extending TH-positive dendrites are largely absent in the young $w v / w v$. The $w v / w v$ also can be distinguished from both homozygous normal $(+/+)$ and $w v / W v$ littermates on P7 based on the appearance of dendrites that are more numerous than in the $w v / w v$ but thin, disorganized, and sparse compared with $+/+$. Most cell death seems to take place in $w V / W v$ before P21. However, at least one subset of dopamine-containing neurons disappears later. The zone of densely packed $\mathrm{TH}$-positive neurons in the substantia nigra that is likely to be the origin of innervation to striosomes in the caudoputamen disappears between P21 and adulthood. Despite the early pathology evident in the mesencephalic dopamine-producing neurons of the $+/ w V$, no evidence for cell death was observed there even in the oldest $+/ w v$ weavers studied.

Key words: developmental effects of weaver; mesencephalic dopamine-containing neurons; cell death in the midbrain; genetic effects on dopamine-containing neurons; genetic causes of cell death; murine mutation weaver; parkinsonism; neurodegeneration
Mutations that act during mammalian development often affect several populations of widely scattered cells, classes of cells for which there is no evident functional commonality. In none of these mutants is there a known common denominator that could account for shared vulnerability. The autosomal recessive murine mutation known as weaver (gene symbol wv) is one of these.

The weaver mutation, localized to distal chromosome 16 (Reeves et al., 1989; Mjaatvedt et al., 1993; Roffler-Tarlov et al., 1994) and likely to be a mutation in a potassium channel (Patil et al., 1995), is known to cause cell death in brain and testes. Weaver compromises differentiation and results in reduced numbers of at least three populations of neurons in the brain and of sperm in the testis. The adult homozygous weaver mouse is depleted of massive numbers of granule cells and numerous Purkinje cells in the cerebellum (Sidman et al., 1965; Rezai and Yoon, 1972; Rakic and Sidman, 1973a,b; Herrup and Trenkner, 1987; Smeyne and Goldowitz, 1989, 1990). Within the ventral midbrain of the adult homozygous weaver, large reductions of tyrusine hydroxylase (TH)-positive neurons occur within cell groups A9 (substantia nigra, pars compacta) and A8 (retrorubral nucleus), whereas cell group A10 [ventral tegmental area (VTA)] is relatively spared (Gupta et al., 1987; Triarhou et al., 1988; Graybiel et al., 1990;

\footnotetext{
Received Aug. 31, 1995; revised Dec. 4, 1995; accepted Dec. 13, 1995.

This work was supported by National Institutes of Health Grant NS20181. We thank Henry Hall for photography and preparation of figures, and Diane Major for help with histology.

Correspondence should be addressed to Dr. Suzanne Roffler-Tarlov, Department of Neuroscience, Tufts University School of Medicine, 136 Harrison Avenue, Boston, MA 02111.

Copyright $\mathcal{C} 1996$ Society for Neuroscience $\quad 0270-6474 / 96 / 161819-08 \$ 05.00 / 0$
}

Smith et al., 1990; Bayer et al., 1994). In addition, a cell-dense zone in A9 bordering A10, which may contribute projections from the midbrain to the striosomal system, is absent in the adult (Graybiel et al., 1990). The lack of dopamine-producing cells in the midbrain of the adult weaver is accompanied by abnormally low dopamine content in the forebrain (Lane et al., 1977; Schmidt et al., 1982; Roffler-Tarlov and Graybiel, 1984, 1986) that is particularly severe in the dorsal striatum (Roffler-Tarlov and Graybiel, 1984, 1986).

Depletion of dopamine and reduced $\mathrm{TH}$ immunoreactivity become evident in the striatum of the weaver during approximately the same postnatal period in which granule cell migration is comprised in the cerebellum (Roffler-Tarlov and Graybiel, 1987). The dopamine content of the caudoputamen of the weaver is not significantly different from that of wild-type at the end of the first postnatal week. Subsequently, however, the content of dopamine in the caudoputamen of the homozygous weaver increases little, whereas that of wild-type increases four- to fivefold (RofflerTarlov and Graybiel, 1987). It is unknown whether the developmental failure of the dopamine-producing system is attributable to lack of dopamine-containing neurons caused by an effect of the mutation on their proliferation, their migration, or their vitality. Therefore, the time of onset of cell loss in the midbrain is of special interest. In the cerebellum of the weaver, the failure of granule cell migration and cell death seem to be linked (Rezai and Yoon, 1972; Rakic and Sidman, 1973a,b), although some granule cells die after successful postnatal migration (Sotelo and Changeux, 1974). If faulty proliferation or migration is implicated in the reduction of the dopamine-containing neurons in weaver, it would be evident postnatally because for these neurons, proliferation 
and cell migration take place before birth (Taber-Pierce, 1973; Specht et al., 1981).

This report focuses on an examination of the midbrains of postnatal mice. We have carried out a quantitative study of the distribution of TH-positive neurons through the entire extent of the mesencephalic cell groups A8 (retrorubral nucleus), A9 (substantia nigra), and A10 (VTA). Counts of individual cells and maps of their positions were made in mice of three genetic types (wild-type, heterozygous weaver, and homozygous weaver). We have compared the numbers and distributions of TH-positive cells in 7-d-old mice with those of 21-d-old and adult mice. This report also presents evidence in support of the view that cell death triggered by weaver occurs after failed terminal differentiation and may be secondary to its effects on neurites.

\section{MATERIALS AND METHODS}

Mice. All mice from which mesencephalic tissue was obtained for the cell counts were on a C57Bl6/6JLe-Awjx CBA/CaGnLeF hybrid background. The animals were of three genetic types: homozygous normal $(+/+)$, heterozygous weaver $(+/ w v)$, and homozygous weaver $(w v / w v)$. All $+/ w v$ and $w v / w v$ mice and most of the $+/+$ mice studied were offspring of heterozygote breeding pairs originally purchased from The Jackson Laboratory (Bar Harbor, ME) and bred and maintained in our colony. Sonle $+/+$ mice were offspring of known $+/+$ pairs on the same hybrid background as the weaver stock; these breeding pairs were also obtained from The Jackson Laboratory.

The midbrains examined were from 7-d-old, 21-d-old, and adult mice. For the 7-d-old groups, two sets of triplet (one each of $+/+,+/ w v$, and $w v / w v)$ littermates were examined. Also examined were a postnatal day 7 (P7; $\mathrm{P0}$ is the day of birth) littermate pair $(w v / w v$ and $+/ w v)$ and $\mathrm{a}+/+$ pup from a known $+/+$ pair. Except for the latter mouse, the pups were selected for study after the formaldehyde perfusion of entire litters of $+/ w v$ breeding pairs.

Because 7-d-old mice cannot be identified with certainty as to genetic type by behavioral characteristics, they were identified by the shape and morphology of the fixed cerebellum, which differs for $+/+,+/ w v$, and $w v / w v$ mice even al this young age. Loss of granule cells is already pronounced in $w v / w v$ and moderate in $+/ w v$ mice. The differential loss of granule cells leads to changes in shape and form of the cerebellum. The $w v / w v$ cerebellum is small and has a pronounced sulcus at the midline, and the $+/ w v$ cerebellum is larger than that of the $w v / w v$ and slightly misshapen and deflated looking compared with that of the $+/+$ mice Histological sections of cerebellum stained for Nissl substance were taken from the cerebellum of each of the mice selected for study to confirm initial identification of $w v / w v,+/ w v$, and $+/+$ pups. Histologically, the $w v / w v$ is characterized by marked depletion of granule cells in the internal granular cell layer and disordered placements of Purkinje cells. The $+/ \mathrm{wv}$ cerebellum is characterized by a disordered Purkinje cell layer, moderate reduction of numbers of granule cells, and out-of-place granule cells.

The 21-d-old mice examined were a triplet of littermates of each genetic type and an additional $+/+$ mouse from the known $+/+$ breeder pairs. Adult tissue was obtained from two sets of 6-month-old triplet littermates of each genetic type, two $w v / w v$ mice that were 9 and 10 months old, and a 9-month-old $+1+$ mouse. The $21-d-o l d$ and adult homozygous weavers were identified by their ataxic behavior, hindlimb weakness, tremor, and by the postmortem appearance of the cerebellum, which is very small compared with $+/+$ and $+/ w v$ littermates. The $+/ w v$ and $+/+$ animals were distinguished from each other by the size and shape of their cerebella after fixation (Roffler-Tarlov and Turey, 1982).

Immunohistochemistry. The brains were fixed by intracardial perfusion of deeply anesthetized mice (Nembutal, $40 \mathrm{mg} / \mathrm{kg}$, i.p.) with $4 \%$ paraformaldehyde in PBS containing $5 \%$ sucrose. The brains were removed, post-fixed for several hours, and placed overnight in a solution of PBS and $20 \%$ sucrose before being frozen at $-70^{\circ} \mathrm{C}$ until processing. The frozen brains were cut in the coronal plane on a sliding microtome into a series of 20 - $\mu \mathrm{m}$-thick sections. A few brains were cut at $30 \mu \mathrm{m}$. The sections were pretreated with methanol, $\mathrm{H}_{2} \mathrm{O}_{2}$, normal goat serum, and Triton X-100 (0.2-2\%). Incubation with $\mathrm{TH}$ antiserum, purchased from Eugene Technologies (Eugene, OR), was carried out for 2-4 d. After incubation, the sections were washed, treated with an IgG bridge, and finally exposed to peroxidase-anti-peroxidase according to Sternberger (1979) and Roffler-Tarlov and Graybiel (1987). Sets of sections from
$+/+,+/ w v$, and $w v / w v$ triplets were processed together, and the sections from the different genetic types were reacted in the same dishes during the final diaminobenzidine steps to ensure identical development of the reaction product. Selected sections were stained for Nissl substance.

Quantitative methods. For counting and spatial mapping of individual TH-stained neurons, the sections were visually oriented in the microscopic field so that the midline of the brain was in a standardized location. This allowed observation of the TH-stained neurons on one side of the midbrain. A custom-made, computerized image-processing system was used to characterize the numbers and positions of the stained cells. Individual sections were aligned with one another by moving the midline of the section into the standardized location described above and by using other fiducial marks such as blood vessels that could be followed through the series.

Individual cells were counted using a camera lucida to superimpose the actual view of the section seen through the eyepieces of the microscope onto a digitized image of the stained cells displayed on a television monitor. Because the monitor image could be observed at the same time as the direct image of the section seen through the camera lucida, the observer could mark individually stained cells with a mouse-driven cursor moved across the image on the monitor while looking througl the microscope. In this way, the fine resolution of the direct image through the microscope was used to determine which cells were appropriate for counting. Counted cells were marked on the digitized image by pushing the mouse button when the cursor was over a cell of interest, and the digitized image was retained as a record of the number and position of the counted cells on the outline of the nucleus.

All TH-positive neurons in which a fragment of the nucleus was visible were counted on one side of the midbrain. Counts were made in evenly spaced, $20-\mu \mathrm{m}$-thick sections, $120 \mu \mathrm{m}$ apart. The neurons in each section were plotted and tabulated with respect to their rostral-caudal and medial-lateral positions. Subsequently, the numbers of counted cells in medial to lateral $100-\mu \mathrm{m}$-wide bins were plotted for each mouse. In this way, the numbers of TH-positive neurons in rostral-to-caudal and medialto-lateral distributions were compiled and histograms plolled for each mouse. Estimates of total numbers of immunostained neurons were made by calculating the areas under the curves of each histogram of the complete series of sections on one side of the brain and then doubling to account for TH-positive neurons on both sides of the midline. Counts were corrected for errors introduced by double counting of split cells using the method of Abercrombie (1946). For the correction, nuclear diameters were measured in at least 50 cells of each type of mouse at each age. No significant differences were found related to age or genetic type. The nuclear diameter for cells from all mice averaged $9.4 \pm 0.1 \mu \mathrm{m}$. To determine the reproducibility of counting, counts on the same side of the brain were repeated using a different series of sections, also $120 \mu \mathrm{m}$ apart, and counts were made also of the TH-positive neurons on the contralateral side of the same brain. The numbers obtained varied by $\leq 5 \%$.

\section{RESULTS}

\section{Quantitative analysis}

\section{Numbers of TH-positive cell bodies in the midbrains of \\ 7-d-old mice}

TH-positive mesencephalic neurons were mapped for $\mathrm{P} 7$ in each of two sets of triplet littermates, in a pair of littermates that were $+/ w v$ and $w v / w v$, and in an independent $+/+$ animal. Figure $1 \mathrm{~A}$ shows the numbers of TH-positive neurons plotted with respect to distance from the midline for one set of triplets. In this comparison, as in all the others made for P7 mice, there was no evidence of significant neuronal loss in the midbrains of the homozygous weaver or in its heterozygous littermate compared with a wildtype littermate. The total corrected numbers of TH-positive mesencephalic neurons for these three mice were 18,200 for the $+/+$, 17,900 for the $+/ w v$, and 18,200 for the $w v / w v$. The mean \pm SEM for corrected numbers of cells for all $\mathrm{P} 7 \mathrm{mice}$ did not differ either. They were $18,400 \pm 2100$ for $+/+$ mice, $17,600 \pm 700$ for $+/ w v$ mice, and 17,300 \pm 1100 for $w v / w v$ mice (Table 1 ).

The spatial distribution of TH-positive midbrain neurons also was similar for the three genetic types (Fig. $1 A$ ). The peak counts were within $\sim 400 \mu \mathrm{m}$ of the midline, in a region that includes cell 
A

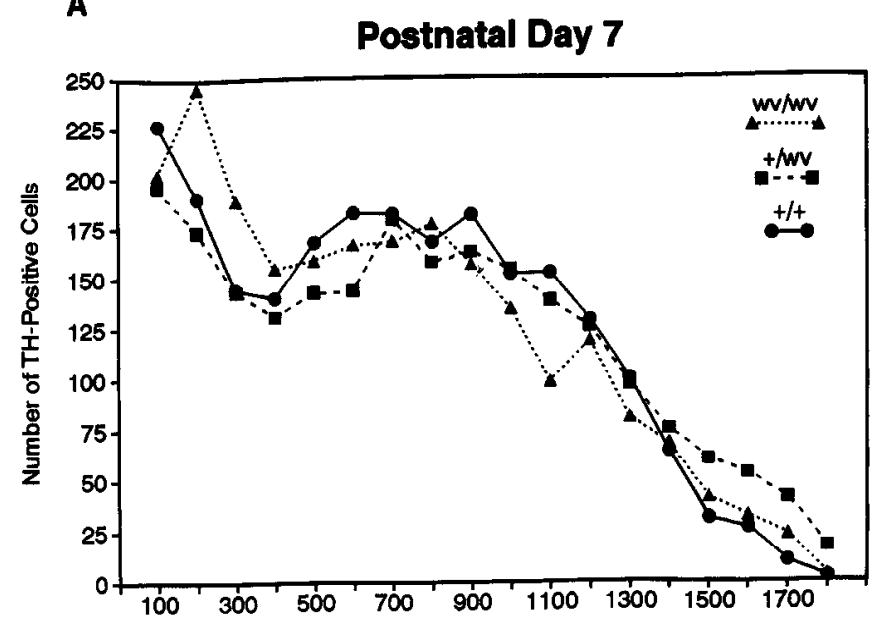

B

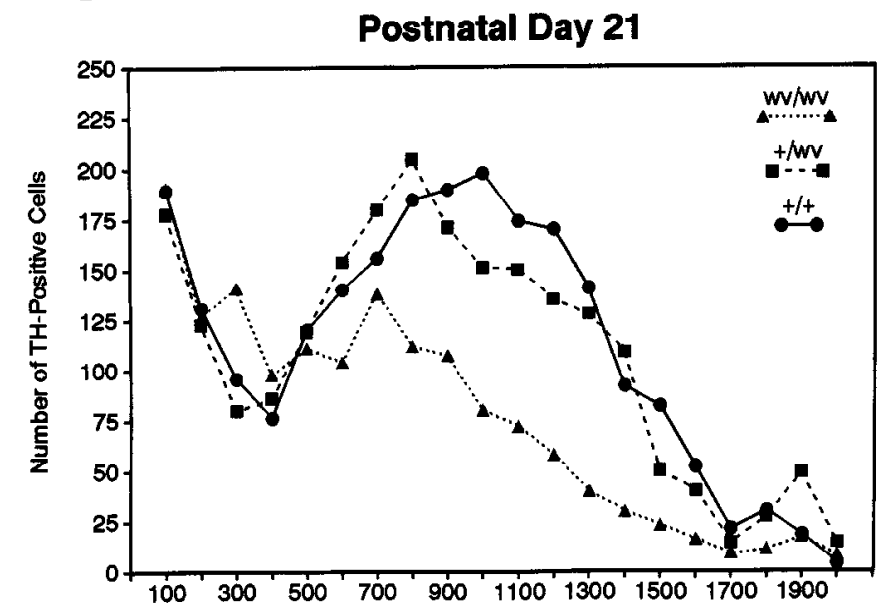

C

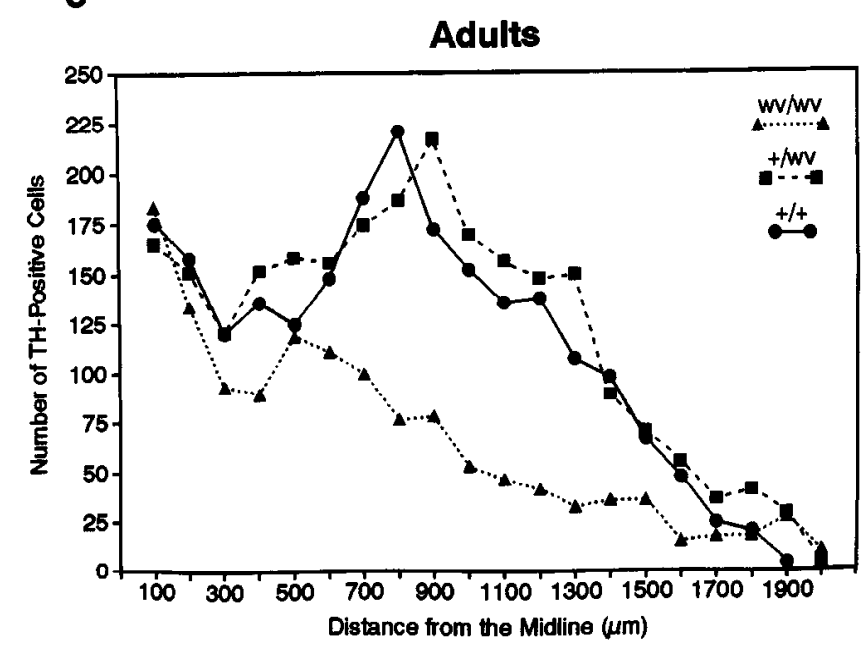

Figure 1. Three charts showing medial to lateral distributions of THpositive neurons in the midbrains of littermate triplets that were $7 \mathrm{~d}, 21 \mathrm{~d}$, and 6 months old. Illustrated are the raw counts of TH-positive neurons present on one side of the midbrain in 100- $\mu$ m-wide vertical strips from the midline to the lateral-most extent in which the TH-positive neurons were found. group A10 (VTA). This region appeared to be more dense with TH-positive cells in the 7-d-old than in older mice (Fig. 1). Farther laterally, the TH-positive cell populations corresponded largely to the neurons of cell group A9 (the substantia nigra, pars compacta) and cell group A8 (the retrorubral nucleus). The medial-to-lateral extent of these TH-positive cell populations was $1700-1800 \mu \mathrm{m}$ for all genetic types.

\section{Numbers of TH-positive neurons in the midbrains of 21-d-old mice}

Counts made of the TH-reactive cells in the midbrains of the two 21 -d-old $+1+$ mice indicated that cell numbers were in the same range as the younger 7-d-old wild-type mice. The corrected mean value was 19,200 (Table 1). The number of TH-positive cells in the midbrain of the 21-d-old $+/ w v$ mouse was also in the same range $(19,700)$. By contrast, the number of TH-positive neurons in the 21 -d-old $w v / w v$ mouse was sharply reduced $(12,600)$. The patterns of spatial distribution of TH-positive neurons were also similar for the $+/+$ and $+/ w v$ mice, but the plot for the $w v / w v$ mouse showed a pronounced reduction in cell number in the middle and lateral regions corresponding to the position of the $\mathrm{A} 8$ and $\mathrm{A} 9$ cell groups (Fig. 1B). A zone of densely packed TII-positive neurons that are a part of A9 on the border of A10 that is largely absent in the adult homozygous weaver (Graybiel et al., 1990) was maintained in the P21 weaver (Fig. 2). This zone is of special interest because it may be the mouse homolog of the densocellular zone found in cat that is a source of TH-positive innervation of striosomes (Jimenez-Castellanos and Graybiel, 1987).

\section{Numbers of TH-positive cells in the midbrains of adult mice}

TH-positive mesencephalic neurons were counted and mapped in two sets of 6-month-old triplet littermates. In addition, three older mice that were between 9 and 10 months old were examined. Two were $w v / w v$ and one was wild-type. The mean \pm SEM value for the total corrected counts for TH-positive neurons in three wildtype adult mice was similar to that for younger mice: $18,700 \pm$ 700 . The mean for counts of TH-positive neurons in the midbrains of the two $+/ w v$ was 20,500 (individual counts were 23,100 and 17,900). Among neurons that die in the $w v / w v$ between P21 and adulthood are those of the dense zone in $\mathrm{A} 9$ as shown in Figure 2 . The reduction in numbers of neurons in $w v / w v$ was significant, whereas no reduction was apparent for the $+/ w v$ (Table 1). The uncorrected counts made for one set of 6-month-old triplets and plotted on the medial-to-lateral axis is shown in Figure $1 C$. The most severe cell loss was observed beginning $\sim 400 \mu \mathrm{m}$ lateral to the midline and extending to $\sim 1700 \mu \mathrm{m}$ from the midline. The mean number of mesencephalic $\mathrm{TH}$-positive neurons in the four $w v / w v$ was $10,800 \pm 600$.

Abnormal TH-positive dendrites in the 7-d-old midbrain of the homozygous weaver and heterozygous weaver mice

Representative transverse sections through the midbrains of 7-dold wild-type and $w v / w v$ littermates are shown in Figure 3. The sections were taken at closely matched, midnigral levels and were stained for TH-like immunoreactivity. In midrostral regions as shown in Figure 3, the clusters of TH-positive cells occupy a region in both the $w v / w v$ and wild-type that has a different shape than that seen in the adult because the cells are more tightly clustered in the young. However, the three principal dopaminecontaining cell groups of the midbrain are visible in each genetic type. The VTA (A10) is in a midline and paramedian position, the rostral part of the retrorubral nucleus (cell group A8) is dorso- 

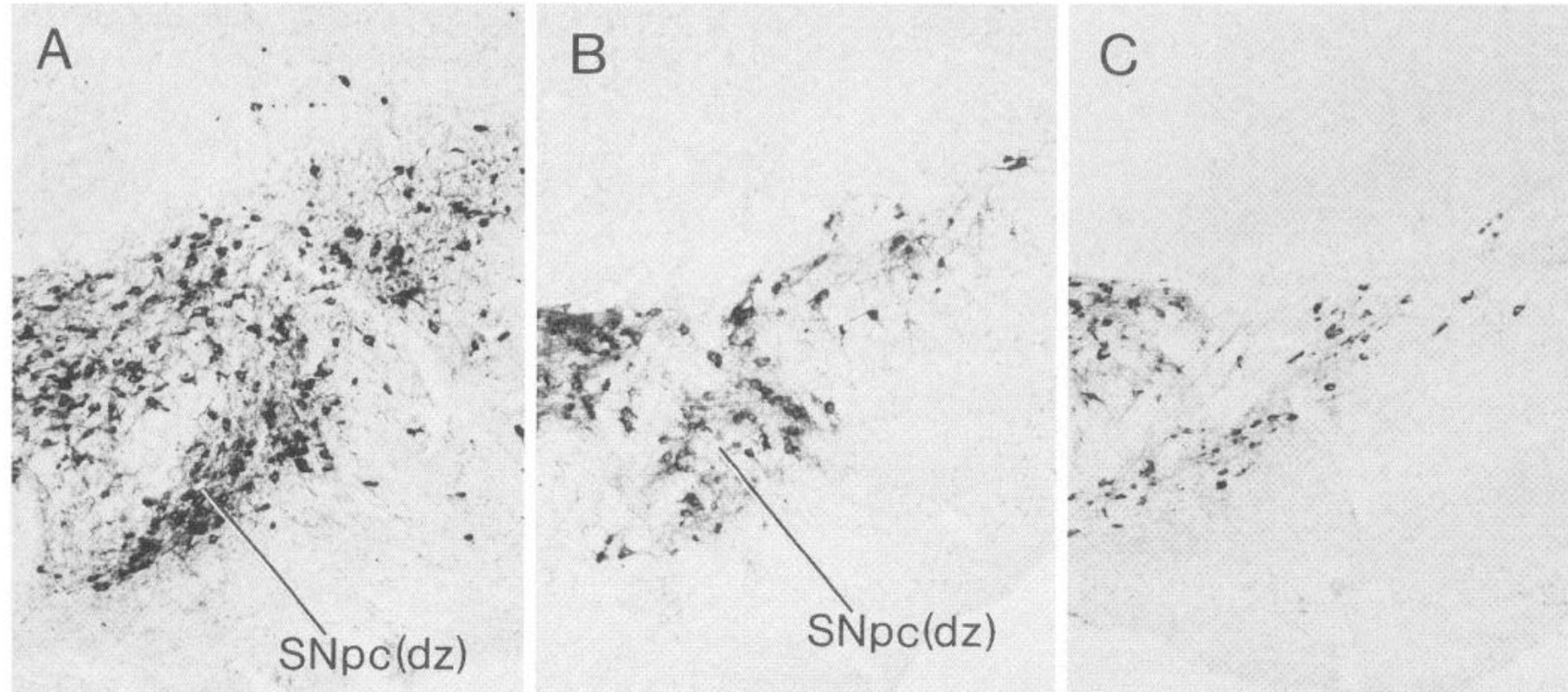

Figure 2. Photomicrographs illustrating the position of the dense zone of TH-positive neurons in the substantia nigra, pars compacta [SNpc(dz)] in transverse sections through the anterior midbrain at the level of the accessory optic tract in 21-d-old wild-type $(A)$, 21-d-old homozygous weaver $(B)$ mice, and in an adult homozygous weaver $(C)$. The densely packed group of TH-positive cells is present in the wild-type $(A)$ and the homozygous weaver $(B)$ mice at P21 when most of the TH-positive cells that are vulnerable to the effects of weaver are gone. Most of the dense zone neurons disappear after P21, as illustrated in $C$. Scale bar, $200 \mu \mathrm{m}$.

lateral to A10, and the substantia nigra, pars compacta itself (cell group A9) is also identifiable.

Despite this general similarity, and the similarity in numbers of TH-positive neurons documented in the quantitative study, there is a dramatic difference in the appearance of the substantia nigra in the two genetic types. In the wild-type neonate (Fig. $3 A$ ), large numbers of TH-positive dendrites extend ventrally from the neurons of the substantia nigra, pars compacta into substantia nigra, pars reticulata. Many of these dendrites reach the ventral limit of the substantia nigra, pars reticulata to terminate abruptly at the border between the substantia nigra and the cerebral peduncle. The TH-positive dendrites form remarkably orderly arrays, appearing at some levels as a densely stained curtain of nearly parallel neurites.

Such long and parallel arrays of TH-positive dendrites were not

\section{Table 1. Total corrected numbers of TH-positive mesencephalic neurons}

\begin{tabular}{llll} 
Age & $+/+$ & $+/ w v$ & $w v / w v$ \\
\hline P7 & $18,400 \pm 2100$ & $17,600 \pm 700$ & $17,300 \pm 1100$ \\
& $(3)$ & $(3)$ & $(3)$ \\
P21 & 19,200 & 19,700 & 12,600 \\
& $(2)$ & $(1)$ & $(1)$ \\
Adults & $18,700 \pm 700$ & 20,500 & $10,800 \pm 600^{*}$ \\
& $(3)$ & $(2)$ & $(4)$
\end{tabular}

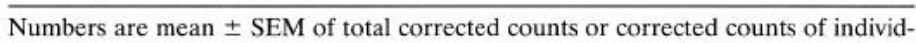
ual mice. Numbers in parentheses are the number of mice in the sample. $P$ is the postnatal day. Two of the adult $+1+$ mice were 6 months old (individual counts: $18,000$ and 18,200$)$ and one was 9 months old $(19,800)$. Both $+/ w v$ adults were 6 months old $(23,000$ and 17,900). Two of the adult homozygous weavers were 6 months old $(11,600$ and 11,100$)$, one was 9 months old $(9,700)$, and one was 10 months old $(10,600)$. The individual corrected counts for the pair of P21 $+/+$ mice were 20,700 and $17,700,{ }^{*} p<0.001$ compared to adult $+/+$ value by Student's $t$-test. found at any level in either the neonatal $w v / w v$ (Fig. $3 B$ ) or $+/ w v$ (Fig. 4). A notable paucity of TH-positive dendrites was characteristic of each P7 $w v / w v$ mouse compared with its $+/+$ control. TH-positive dendrites extending through the substantia nigra, pars reticulata were nearly nonexistent in the mutants (Fig. $3 B$ ). In the 7-d-old $+/ w v$ mouse a few ventrally extending TH-positive dendrites were present, and they had a wispy and less organized appearance than those of the wild-type dendrites (Fig. 4).

Interestingly, the territory occupied by the ventrally extending dendritic fascicles and individual dendrites in the wild-type substantia nigra, pars reticulata appeared to be restricted ventrally by a border between the substantia nigra, pars reticulata and the ventrally situated cerebral peduncle. The dendrites do not appear to invade the peduncle but, instead, extended to it and then ended or turned away. This border was invisible in the $w v / w v$ pups because TH-positive dendrites did not reach it; no TH-positive staining was seen in the $w v / w v$ near the ventral border of the substantia nigra, pars reticulata. The $+/ w v$ displayed an intermediate pattern. Some ventrally extending dendrites existed in the $w v / w v$ mice, and it was possible to follow them from their origin into the substantia nigra, pars reticulata, but they did not extend through the substantia nigra, pars reticulata to its border with the cerebral peduncle.

The defect in the brains of the $w v / w v$ and $+/ w v$ were most readily apparent at the levels shown in Figures 3 and 4, but it was also visible at all anteroposterior levels of the nigral complex, including cell group A8.

The TH-positive cell bodies in the substantia nigra, pars compacta of the wild-type mice seen at this and other levels display a variety of sizes and shapes and of intensity of TH staining. Although TH immunohistochemistry is not a quantitative technique, there was a consistent pattern found in the staining of the normal 

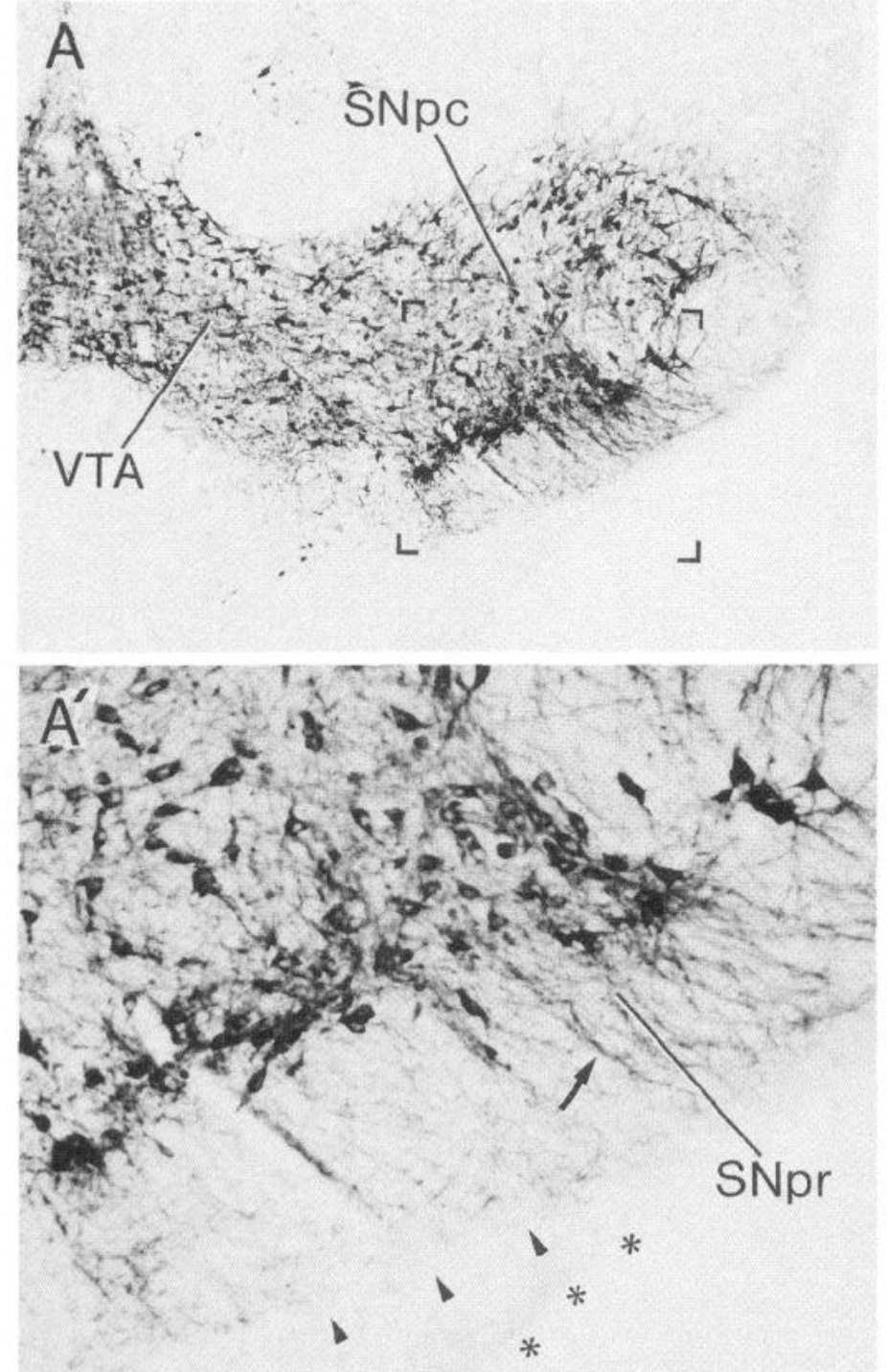

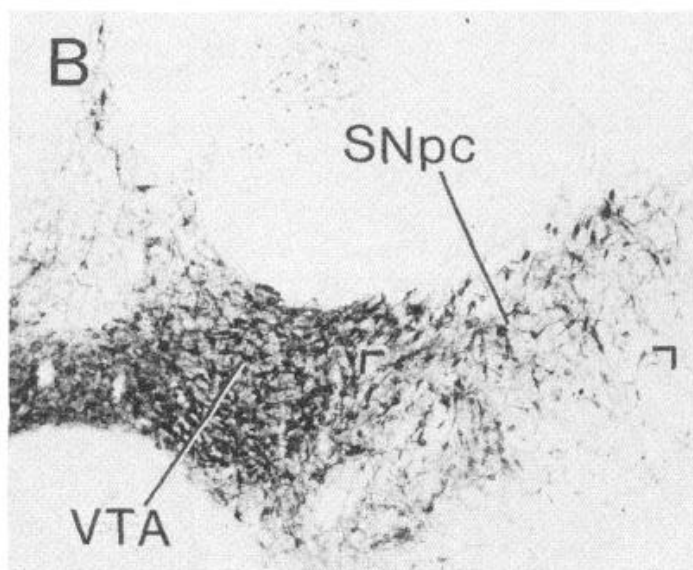

\lrcorner

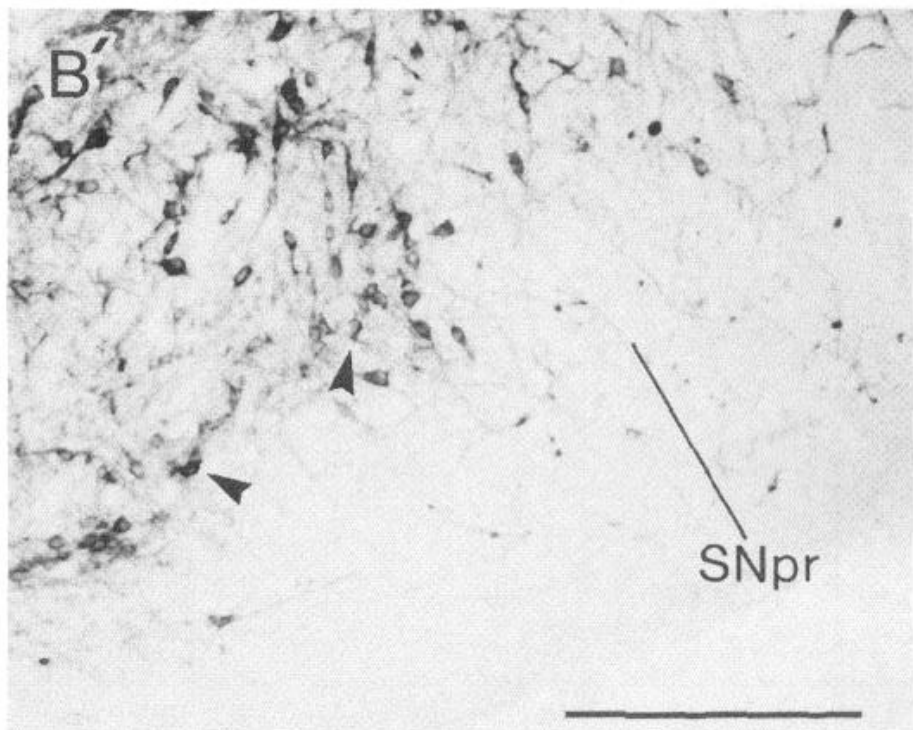

Figure 3. Photomicrographs illustrating sections through the anterior part of the substantia nigra, pars compacta ( $S N p c)$ in a 7-d-old wild-type mouse $\left(A, A^{\prime}\right)$ and a 7-d-old homozygous weaver mouse $\left(B, B^{\prime}\right)$. The medial forebrain bundle and anterior $V T A$ contain TH-immunostained processes in each genotype, and in each the main body of the $\mathrm{SNpc}$ is evident as a collection of TH-positive cell bodies and neuropil. In the wild-type mouse $\left(A, A^{\prime}\right)$, many delicate TH-positive dendrites stream from this cell layer into the underlying pars reticulata of the substantia nigra (SNpr). Among them are scattered $\mathrm{TH}$-positive cell bodies. In the homozygous weaver animal $\left(B, B^{\prime}\right)$, many well stained cells are found in the SNpc and no evident cell loss is found at this level by cell counting, but the sheet of ventrally extending TH-positive dendrites is nearly absent. There is also a notable lack of TH-positive neuropil associated with the TH-positive neurons. Higher-power views of these features are shown for the wild-type in $A^{\prime}$ (bracketed area in $A$ ) and homozygous weaver in $B^{\prime}$ (bracketed area in $B$ ). The dense sheet of ventrally oriented TH-positive dendrites shown in $A^{\prime}$ (arrow) is not present in the homozygous weaver $\left(B^{\prime}\right)$, although neurons of the ventral tier of the substantia nigra, pars compacta appear to be present (arrowheads). The arrowheads in $A^{\prime}$ mark the boundary between the ventral border of the substantia nigra, pars reticulata and the cerebral peduncle. The wild-type TH-positive dendrites do not invade the territory of the cerebral peduncles. The asterisks indicate the ventral edge of the midbrain. Scale bars, $200 \mu \mathrm{m}$.

substantia nigra in that large, laterally placed cells were always stained more darkly than the clusters of TH-positive neurons that were medially placed. The cells in the substantia nigra of the weaver did not show such a variety of size of neuronal soma; all appeared to be more uniformly small, as noted earlier by Smith et al. (1990), closely packed, and less intensely stained than those in normal littermates. The one apparent increase in the $w v / w v$ was in the intensity of staining of fibers in the VTA (Fig. 3).

\section{DISCUSSION}

The results of this study demonstrate that normal numbers of TH-positive neurons have normal distributions in the midbrains of $w v / w v$ and $+/ w v$ mice at least until P7, after which substantial loss of TH-positive cells occurs in the region occupied by the substantia nigra and the retrorubral nucleus of the $w v / w v$ only. The fact that normal numbers of dopamine-containing mesencephalic neurons can be detected by TH immunocytochemistry at P7 suggests that the early development of these neurons including proliferation, lineage decisions, migration, and transmitter expression occur normally in weaver mice. However, our findings clearly establish that the nigral complex is already abnormal in both $w v / w v$ and $+/ w v$ mice by $\mathrm{P} 7$, because the normal array of $\mathrm{TH}-$ containing dendrites of the nigral neurons is sharply diminished. This finding suggests that abnormalities in neurite extension or maintenance may precede death of the dopamine-containing neurons in the $w v / w v$ mice. The single weaver allele carried by the 
Figure 4. Photomicrograph illustrating TH immunostaining in the substantia nigra of a $7-\mathrm{d}$ old heterozygous weaver mouse. Although no cell loss was found in 7-d-old or older heterozygotes, there are few TH-positive dendrites present at $\mathrm{P} 7$ in the substantia nigra, pars reticulata $(\mathrm{SNpr})$ of the heterozygote weaver, and these tend to be disordered (arrows). Scale bar, $200 \mu \mathrm{m}$.

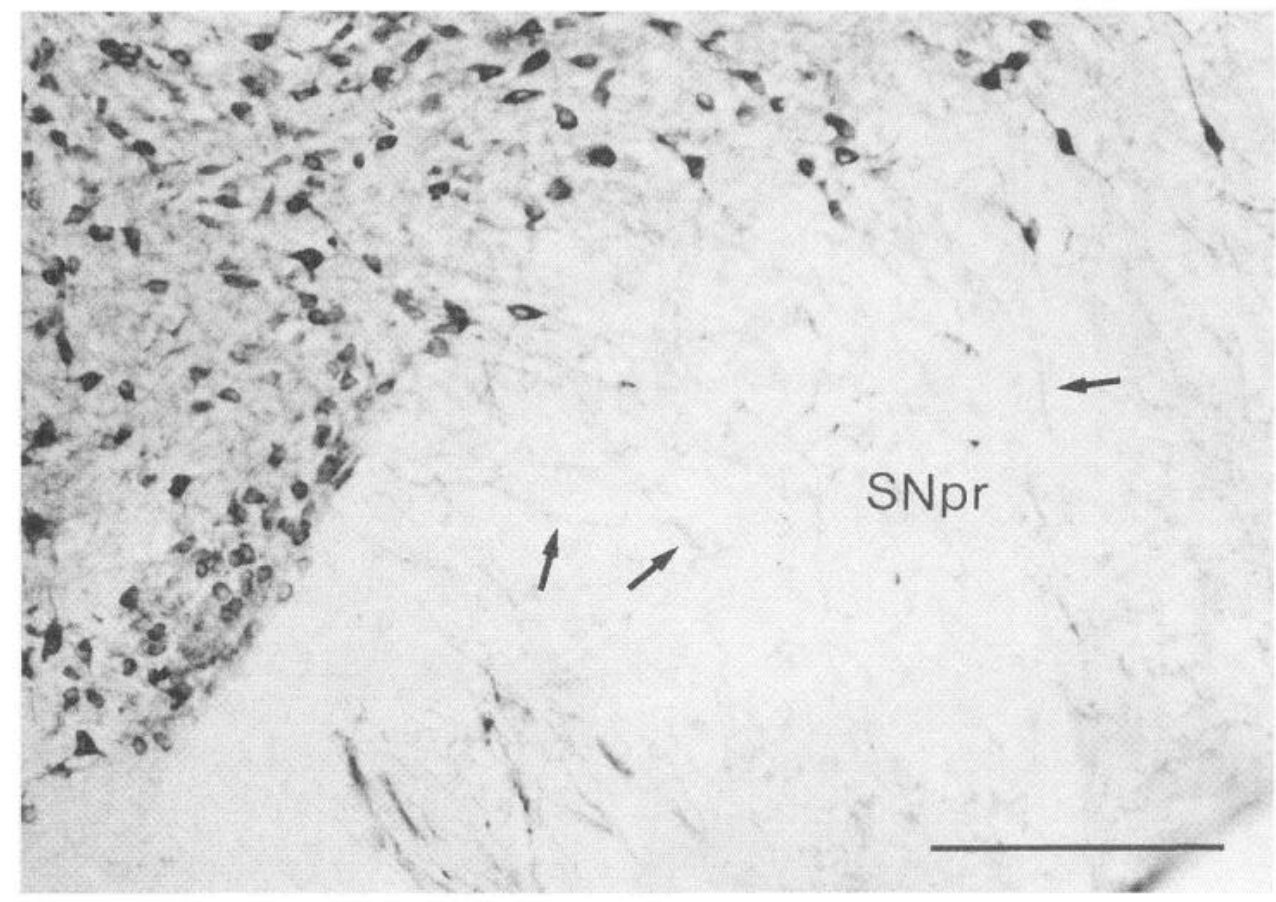

$+/ w v$ affects neurites but does not cause the death of the cell bodies.

\section{The timing and pattern of cell death in the midbrain of the weaver}

Most of the vulnerable TH-positive mesencephalic neurons disappear before P21, the next youngest age studied. Thus, the timing of cell death in the midbrain points to its taking place during final differentiation of the dopamine-containing populations, when the axons that originate in the midbrain complete the innervation of their striatal targets, and the dopamine content of the caudoputamen and ventral striatum achieves adult levels (Roffler-Tarlov and Graybiel, 1987). Our earlier developmental study showed that whereas dopamine content of the wild-type caudoputamen increases rapidly after the first postnatal week, that of the $w v / w v$ barely changes (Roffler-Tarlov and Graybiel, 1987). These results can now be accounted for by loss of cells during the second and third postnatal weeks in $w v / w v$.

Premature cell death is a feature shared by at least three of the four cell types known to be targets of weaver. Histologically, cell death caused by weaver is easily visible only in the testis, where degenerating germ cells are evident after P28 among spermatids undergoing final differentiation (Harrison and Roffler-Tarlov, 1994). In older $w v / w v$ males, degeneration engulfs massive numbers of germ cells at nearly every developmental stage (Vogelweid et al., 1993; Harrison and Roffler-Tarlov, 1994). Within the cerebellum, where both granule cells and Purkinje cells are direct cellular targets of weaver (Goldowitz and Mullen, 1982; Goldowitz, 1989; Smeyne and Goldowitz, 1990), degeneration is not readily apparent. Although Purkinje cells are depleted in the cerebellum of the weaver, there is no evidence that points to cell death as the cause (Herrup and Trenkner, 1987; Smeyne and Goldowitz, 1990). Granule cell proliferation is normal or near normal in weaver, yet granule cells are depleted without readily apparent degeneration, although some degenerating profiles can be detected in the external germinal zone (Smeyne and Goldowitz, 1989).

Degenerating neurons are not readily seen in the midbrain of the weaver either. However, we believe that lack of detectable dopamine-containing neurons in $w v / w v$ is attributable to cell death rather than to their becoming undetectable because of loss of TH immunoreactivity, as occurs in some populations of deafferented TH-positive neurons (Baker et al., 1983). There are several pieces of evidence to support the claim that the neurons die as opposed to having been retained after loss of the TH-positive phenotype. The first is that the region occupied by the substantia nigra, pars compacta appears cell-poor in neuronal stains in the adult $w v / w v$ (Schmidt et al., 1982) and a cell sparse region is seen in the place of the TH-positive "dense zone" in the medial substantia nigra in Nissl-stained sections of the midbrain of the adult weaver (Graybiel et al., 1990). Furthermore, we find fewer cells in the 30-d-old substantia nigra of the weaver that have been marked with a retrograde label (Fluoro-gold) injected into the striatum at P2 than are evident in the substantia nigra of 7-d-old weavers (Martin and Roffler-Tarlov, 1993). Degeneration of the vulnerable neurons may be difficult to see if cell death and subsequent engulfment of debris occur very quickly. However, we reported recently the presence of dying cells in the substantia nigra of the weaver observed by silver staining (Oo et al., 1995). The appearance of fewer TH-positive neurons in the dense zone in the adult weavers compared with P21 weavers, as reported here, fits well with evidence published previously of the persistence of the THpositive striosomes in the midst of the TH-poor matrix in the caudoputamen of 21-d-old weavers (Roffler-Tarlov and Graybiel, 1987). The TH-positive staining of striosomes disappears in the adult weaver, indicating that the death of their cells of origin occurs after P21 (Roffler-Tarlov and Graybiel, 1987).

The signal for cell death is unknown for any of the cell populations targeted by weaver. Little is known about whether vulnerable cell populations are subject to death by apoptosis, an intrinsic cell-death program that is distinguished by distinct morphological characteristics, often involves the activation of genes, and is associated with "naturally occurring cell death," the programmed death of neurons during development (Wyllie, 1987; Williams and Smith, 1993). There are recent preliminary observations of apop- 
totic processes by in situ end labeling of DNA fragments that occur in the external granular layer of the cerebellum and testis, but not in the midbrain, of the developing weaver (Harrison and Roffler-Tarlov, 1995). The study of silver-stained sections pointed to at least some cell death in the midbrain of the weaver occurring via nonapoptotic, non-necrotic mechanisms (Oo et al., 1995). We show here that the majority of cell death in the midbrain of the weaver occurs between P7 and P21, a period corresponding to the time at which naturally occurring developmental cell death occurs in the substantia nigra, pars compacta in rat (Janec and Burke, 1993).

It seems possible that abnormal cell death in weaver could be caused by an unchecked extension of naturally occurring cell death in the substantia nigra complex. We have found no evidence as yet for developmental cell death among TH-positive neurons in the wild-type midbrain. However, naturally occurring cell death may be particularly difficult to detect among the dopaminecontaining neurons of the ventral midbrain, because the numbers of neurons potentially expressing $\mathrm{TH}$ are regulated developmentally as well as genetically (Ross et al., 1976; Baker et al., 1980, 1982; Reis et al., 1981). Baker and her colleagues have suggested that some strain differences in the numbers of TH-positive neurons in the mouse midbrain arise not because of differences in the numbers of neurons generated or differences in rates of ccll death, but because of an increase in numbers of neurons that express $\mathrm{TH}$ postnatally (Baker and Reis, 1986). Conceivably, an increase in TH expression in existing neurons during development could mask a loss in cell number in the wild-type.

Although there are few clues as to the cause of cell death in the midbrain of the weaver, one correlation noted is the presence of calbindin-D28K in the relatively unaffected dopamine-containing cell groups of the midbrain A10 cell group and the dorsal tier of the A9 cell group of the weaver (Gaspar et al., 1994). It is possible that weaver acts in all of the mesencephalic dopamine-containing cell groups and that protection is conferred to those that contain calbindin.

\section{Early defects in the neurites of dopamine-containing neurons in the midbrain of the weaver}

The sccond major finding of this study is that already by P7, abnormalities in the neurites of $\mathrm{TH}$-expressing neurons are evident in the substantia nigra of the weaver. weaver may have an effect on neurite formation that precedes cell death and may even influence its occurrence. This suggestion is supported by two previous sets of findings on the dopamine-containing neurons of the weaver.

First, although the medially placed VTA (cell group A10) is relatively spared with regard to cell death (Roffler-Tarlov and Graybiel, 1984, 1986; Gupta et al., 1987; Triarhou et al., 1988; Graybiel et al., 1990; Bayer et al., 1994) (for review, see Quinn et al., 1990; Roffler-Tarlov, 1992), the mesostriatal tract does not escape the actions of weaver. High-affinity uptake of $\left[{ }^{3} \mathrm{H}\right]$ dopamine by synaptosomes prepared from the targets of the VTA is decreased. This finding suggests that the effects of weaver may be expressed by the processes of the dopamine-containing cells that arc sparcd massive cell death (Roffler-Tarlov et al., 1990).

Second, gene dose dependence has been demonstrated for the effects of weaver on the nigrostriatal system. The content of endogenous dopamine is reduced in the caudoputamen and olfactory tubercle of the $+/ w v$ compared with wild-type (RofflerTarlov and Graybiel, 1986), and the dendrites of the adult $+/ w v$ are shortened (Triarhou et al., 1989). Our findings demonstrate that the heterozygote effect on neurites is present as early as P7. Both at P7 and at adulthood, these effects occur in the absence of changes in cell number, perhaps because such effects are less severe in the heterozygote.

The effects of weaver on neurite extension and maturation could be causally unrelated to those leading to cell death. However, it is possible that defective processes could put cells in jeopardy in an environment that is quite safe for a normal cell. For example, faulty structure could lead to a failure of the vulnerable cells to interact with other cells or to obtain trophic factors necessary for viability. Evidence gathered from observations of both the mesencephalic dopamine-containing neurons and the granule cells of the cerebellum points to neurites as a cellular target of the mutant gene (Willinger and Margolis, 1985a,b; Hatten et al., 1986; Doucet et al., 1989; Triarhou and Ghetti, 1989; Roffler-Tarlov et al., 1990; Gao et al., 1992). The alterations found in Purkinje cell dendrites of weaver micc have becn interpreted as bcing sccondary to failure of synapse formation (Sotelo, 1975). It seems possible, however, that that such changes, rather than being attributable to epigenetic factors, may instead also reflect intrinsic defects in neurites. More generally, we raise the possibility that neurite extension and maintenance may be a primary target of the weaver gene in several classes of neurons and that a similar failure of final differentiation may underlie the death of the male germ cells in weaver mice.

As has been noted previously, the pattern of cell death in the dopamine-containing cell groups of adult weaver midbrains bears remarkable parallels to that occurring in Parkinson's disease and in Parkinsonian conditions in humans and animals caused by the administration of 1-methyl-4-phenyl-1,2,3,6-tetrahydropyridine (or MPTP). The hallmarks of the shared pattern are loss of TH-positive neurons in the substantia nigra, pars compacta and the retrorubral nucleus and relatively greater retention of neurons in the medially placed VTA. The present study adds to the similarities in pointing out that, as in Parkinson's disease, loss of dopamine-containing cells caused by weaver is attributable to cell death occurring after cell proliferation and migration have taken place. The results of this study emphasize that the normal product of the weaver locus is necessary for the vitality of this subset of dopamine-containing neurons.

\section{REFERENCES}

Abercrombie M (1946) Estimation of nuclear population from microtome sections. Anat Rec 94:239-247.

Baker H, Reis DJ (1986) Developmental mechanisms which may account for strain differences in the number of dopamine neurons in the midbrain. In: Biological psychiatry (Shagass C, Josiassen RC, Bridger WH, Weiss KJ, Stoff D, Simpson GM, eds), pp 28-30. New York: Elsevier. Baker H, Joh TH, Reis DJ (1980) Genetic control of number of midbrain dopaminergic neurons in inbred strains of mice: relationship to size and neuronal density of the striatum. Proc Natl Acad Sci USA $77: 4369-4373$.

Baker H, Joh TH, Reis DJ (1982) Time of appearance during development of differences in nigrostriatal tyrosine hydroxylase activity in two inbred mouse strains. Dev Brain Res 4:157-165.

Baker H, Kawano T, Margolis FL, Joh TH (1983) Transneuronal regulation of tyrosine hydroxylase expression in olfactory bulb of mouse and rat. J Neurosci 3:69-78.

Bayer SA, Triarhou LC, Thomas JD, Ghetti B (1994) Correlated quantitative studies of the neostriatum, nucleus accumbens, substantia nigra, and ventral tegmental area in normal and weaver mutant mice. J Neurosci 14:6901-6910.

Doucet G, Brundin P, Seth S, Murata Y, Strecker RE, Triarhou LC, Ghetti B, Björklund A (1989) Degeneration and graft-induced restoration of dopamine innervation in the weaver mouse neostriatum: a 
quantitative radioautographic study of $\left[{ }^{3} \mathrm{H}\right]$ dopamine uptake. Exp Brain Res 77:552-568.

Gao W-Q, Liu X-L, Hatten ME (1992) The weaver gene encodes a nonautonomous signal for CNS neuronal differentiation. Cell 68:841-854.

Gaspar P, Ben Jelloun N, Febvret A (1994) Sparing of the dopaminergic neurons containing calbindin- $\mathrm{D}_{28 \mathrm{k}}$ and of the dopaminergic mesocortical projections in weaver mutant mice. Neuroscience 61:293-305.

Goldowitz D (1989) The weaver granuloprival phenotype is due to intrinsic action of the mutant locus in granule cells: evidence from homozygous weaver chimeras. Neuron 2:1565-1575.

Goldowitz D, Mullen RJ (1982) Granule cell as a site of gene action in the weaver mouse cerebellum: evidence from heterozygous mutant chimeras. J Neurosci 2:1474-1485.

Graybicl AM, Ohta K, Roffler-Tarlov S (1990) Patterns of cell and fiber vulnerability in the mesostriatal system of the mutant mouse weaver. I. Gradients and compartments. J Neurosci 10:720-733.

Gupta M, Felten DL, Ghetti B (1987) Selective loss of monoaminergic neurons in weaver mutant mice: an immunocytochemical study. Brain Res 402:379-382.

Harrison SMW, Roffler-Tarlov S (1994) The male-sterile phenotype of the neurological mutant mouse weaver. Dev Dynamics 200:26-38.

Harrison SMW, Roffler-Tarlov S (1995) Apoptotic and non-apoptotic cell death in the mouse mutant weaver. Soc Neurosci Abstr 424:16.

Hatten ME, Liem RKH, Mason CA (1986) Weaver mouse cerebellar granule neurons fail to migrate on wild-type astroglial processes in vitro. J Neurosci 6:2676-2683.

Herrup K, Trenkner E (1987) Regional differences in cytoarchitecture of the weaver cerebellum suggest a ncw model for wcavcr genc action. Neuroscience 23:871-885.

Janec E, Burke RE (1993) Naturally occurring cell death during postnatal development of the substantia nigra pars compacta of rat. Mol Cell Neurosci 4:30-35.

Jiménez-Castellanos J, Graybiel AM (1987) Subdivisions of the dopamine-containing A8-A9-A10 complex identified by their differential mesostriatal innervation of striosomes and extrastriosomal matrix. Neuroscience 23:223-242.

Lane JD, Nadi NS, McBride WJ, Aprison MH, Kusano K (1977) Contents of serotonin, norepinephrine and dopamine in the cerebrum of the 'staggerer,' 'weaver' and 'nervous' neurologically mutant mice. J Neurochem 29:349-350.

Martin B, Roffler-Tarlov S (1993) The early-forming projections of the substantia nigra in the mutant mouse weaver. Soc Neurosci Abstr 586:12.

Mjaatvedt AE, Citron MP, Reeves RH (1993) High-resolution mapping of D16Led-1, Gart, Gas-4, Cbr, Pcp-4, and Erg on distal mouse chromosome 16. Genomics 17:382-386.

Oo TF, Henchcliffe C, Harrison SMW, Roffler-Tarlov SK, Burke RE (1995) Neuronal cell death in weaver substantia nigra is non-apoptotic. Soc Neurosci Abstr 424:15.

Patil N, Cox DR, Bhat D, Faham M, Myers RM, Peterson AS (1995) A potassium channel mutation in weaver mice implicates membrane excitability in granule cell differentiation. Nature Genet 11:126-129.

Quinn B, Graybiel AM, Moratalla R, Langston JW, Roffler-Tarlov S, Ohta K (1990) Patterns of vulnerability of mesostriatal neurons. In: Advances in behavioral biology (Nagatsu T, Fisher A, Yoshida M, eds), pp 207-212. New York: Plenum.

Rakic P, Sidman RL (1973a) Sequence of developmental abnormalities leading to granule cell deficit in cerebellar cortex of weaver mutant mice. J Comp Neurol 152:103-132.

Rakic P, Sidman RL (1973b) Organization of cerebellar cortex secondary to deficit of granule cells in weaver mutant mice. J Comp Neurol 152:133-161.

Reeves RH, Crowley MR, Lorenzon N, Pavan WJ, Smeyne RJ, Goldowitz D (1989) The mouse neurological mutant weaver maps within the region of chromosome 16 that is homologous to human chromosome 21. Genomics 5:522-526.

Reis DJ, Baker H, Fink JS, Joh TH (1981) A genetic control of the number of dopamine neurons in mouse brain: its relationship to brain morphology, chemistry, and behavior. In: Genetic research strategies for psychobiology and psychiatry (Gershon ES, Matthysse S, Breakefield XO, Ciaranello RD, eds), pp 215-229. New York: Boxwood.
Rezai Z, Yoon CH (1972) Abnormal rate of granulc cell migration in the cerebellum of "weaver" mutant mice. Dev Biol 29:17-26.

Roffler-Tarlov S (1992) The weaver mutation: a murine paradigm of Parkinson's disease. In: Progress In Parkinson's disease, Vol 2, (Weiner WJ, Hefti F, eds), pp 363-374. Mt. Kisco, NY: Futura.

Roffler-Tarlov S, Turey M (1982) The content of amino acids in the developing cerebellar cortex and deep cerebellar nuclei of granule cell deficient mutant mice. Brain Res 247:65-73.

Roffler-Tarlov S, Graybiel AM (1984) Weaver mutation has differential effects on the dopamine-containing innervation of the limbic and nonlimbic striatum. Nature 307:62-66.

Roffler-Tarlov S, Graybiel AM (1986) Expression of the weaver gene in dopamine-containing neural systems is dose-dependent and affects both striatal and nonstriatal regions. J Neurosci 6:3319-3330.

Roffler-Tarlov S, Graybiel AM (1987) The postnatal development of the dopamine-containing innervation of dorsal and ventral striatum: effects of the weaver gene. J Neurosci 7:2364-2372.

Roffler-Tarlov S, Pugatch D, Graybiel AM (1990) Patterns of cell and fiber vulnerability in the mesostriatal system of the mutant mouse weaver. II. High affinity uptake sites for dopamine. J Neurosci 10:734-740.

Roffler-Tarlov S, Cheng S, Lin CS, Wensley CH, Graybiel AM, Gusella JF (1994) The chromosomal location of the murine mutation weaver Neurodegeneration 3:61-72.

Ross RA, Judd AB, Pickel VM, Joh TH, Reis DJ (1976) Straindependent variations in number of midbrain dopaminergic neurones. Nature 264:654-656.

Schmidt MJ, Sawyer BD, Perry KW, Fuller RW, Foreman MM, Ghetti B (1982) Dopamine deficiency in the weaver mutant mousc. J Ncurosci 2:376-380.

Sidman RL, Green MC, Appel SH (1965) Catalog of the neurological mutants of the mouse. Cambridge: Harvard UP.

Smeyne RJ, Goldowitz D (1989) Development and death of external granular layer cells in the weaver mouse cerebellum: a quantitative study. J Neurosci 9:1608-1620.

Smeyne RJ, Goldowitz D (1990) Purkinje cell loss is due to a direct action of the weaver gene in Purkinje cells: evidence from chimeric mice. Dev Brain Res 52:211-218.

Smith III MW, Cooper TR, Joh TH, Smith DE (1990) Cell loss and class distribution of TH-I cells in the substantia nigra of the neurological mutant, weaver. Brain Res 510:242-250.

Sotelo C (1975) Dendritic abnormalities of Purkinje cells in the cerebellum of neurologic mutant mice (weaver and staggerer). Adv Neurol 12:335-351.

Sotelo C, Changeux JP (1974) Bergmann fibers and granular cell migration in the cerebellum of homozygous weaver mutant mouse. Brain Res $77: 484-491$.

Specht LA, Pickel VM, Joh TH, Reis DJ (1981) Light-microscopic immunocytochemical localization of tyrosine hydroxylase in prenatal rat brain. I. Early ontogeny. J Comp Neurol 199:233-253.

Sternberger LA (1979) Immunohistochemistry. New York: Wiley.

Taber Pierce E (1973) Time of origin of neurons in the brain stem of the mouse. Prog Brain Res 40:53-65.

Triarhou LC, Ghetti B (1989) The dendritic dopamine projection of the substantia nigra: phenotypic denominator of weaver gene action in hetero- and homozygosity. Brain Res 501:373-381.

Triarhou LC, Norton J, Ghetti B (1988) Mesencephalic dopamine cell deficit involves areas A8, A9, and A10 in weaver mutant mice. Exp Brain Res 70:256-265.

Vogelweid CM, Verma T, Norton J, Harruff R, Ghetti B (1993) Hypospermatogenesis in the cause of infertility in the male weaver mutant mouse. J Neurogenet 9:89-104.

Williams GT, Smith CA (1993) Molecular regulation of apoptosis: genetic controls on cell death. Cell 74:777-779.

Willinger M, Margolis DM (1985a) Effect of the weaver (wv) mutation on cerebellar neuron differentiation. I. Qualitative observations of neuron behavior in culture. Dev Biol 107:156-172.

Willinger M, Margolis DM (1985b) Effect of the weaver (wv) mutation on cerebellar neuron differentiation. II. Quantitation of neuron behavior in culture. Dev Biol 107:173-179.

Wyllie AH (1987) Apoptosis: cell death in tissue regulation. J Pathol 153:313-316. 